\title{
Impact of Academic Detailing and Same-Day Reminders on Monitoring for Iron Deficiency in Patients With Heart Failure in a Family Medicine Residency
}

\author{
Stacey Karl, PharmD, BCPS | Jeffrey Walden, MD | Peter Koval, PharmD, BCPS
}

Published: 8/8/2017 | DOI: 10.22454/PRiMER.2017.474101

\section{Abstract}

Introduction: As we move from a fee-for-service system to a value-based payment system, ongoing quality improvement projects have become the norm. We chose to evaluate whether academic detailing by a pharmacist is an effective means of increasing knowledge among family medicine residents of the need to monitor for iron deficiency in chronic heart failure (CHF) patients.

Methods: We identified the baseline number of iron levels obtained for CHF patients and surveyed all 24 residents to evaluate baseline knowledge of the association between iron deficiency and CHF. Residents met with a pharmacist on clinic days to discuss iron deficiency and CHF and received an educational handout and a list of their CHF patients. Periodic reminders were first sent electronically to residents followed by in-person reminders from the pharmacist for patients seen that day in clinic.

Results: At baseline, 16 (3\%) of $488 \mathrm{CHF}$ patients had an iron level collected within the past year. Initial survey results showed only one resident (4.2\%) reported knowledge of monitoring iron in CHF patients. After academic detailing, residents ordered iron panels on 234 patients. Of these, 98 patients (42\%) were found to be iron deficient. On postintervention analysis, all residents surveyed (20) reported that they would monitor iron in CHF patients $(P<0.001)$. Residents were receptive to academic detailing and preferred it over EMR messages.

Conclusion: Education from a pharmacist improved awareness of the necessity to evaluate for iron deficiency in $\mathrm{CHF}$ patients. Academic detailing with reminders is a viable option for improving quality and educating residents.

\section{Introduction}

Despite almost 2 decades of research demonstrating a need to increase the quality of care provided to patients, wide variations in care still exist. ${ }^{1,2}$ Recent changes in the health care system, such as a move from fee-for-service to value-based payment, may provide the momentum to support reducing these variations in care. Ongoing quality improvement projects have therefore now become commonplace in clinical practice, and have been incorporated under the "improved population health" platform of the triple aim. ${ }^{3}$

One means of improving adherence to quality metrics and improving patient care is use of academic detailing. The Centers for Disease Control and Prevention defines academic detailing as "structured visits by trained personnel to health care practices for the purpose of delivering tailored training and technical assistance to health care providers to help them use best practices." ${ }^{4}$ Despite the literature surrounding academic detailing and its use in private 
practice and inpatient academic settings, ${ }^{5,6}$ and despite calls to incorporate curriculum on the broader changes in health care into residency training, ${ }^{7}$ there are still few studies that evaluate the effectiveness of this intervention.

We chose to evaluate the association between iron deficiency and CHF because of the ubiquity of CHF in ambulatory care, ${ }^{8}$ its cost to the health system, ${ }^{9}$ and the increasing numbers of studies demonstrating the prevalence of iron deficiency in CHF patients ${ }^{10-14}$ and symptomatic improvement with iron supplementation. ${ }^{15}$ The 2016 European Society of Cardiology Guidelines recommends that CHF patients undergo an evaluation of iron status. ${ }^{16}$ The 2013 ACCF/AHA Guideline for the Management of Heart Failure deferred making specific monitoring recommendations regarding iron deficiency in CHF but noted that anemia almost doubles mortality risk in CHF patients. ${ }^{17}$ Yet, despite increasing evidence that iron deficiency in CHF patients is associated with worse outcomes, ${ }^{14,15}$ this is not a typical quality metric assessed in CHF patients. We believed using a lesser-known metric would better demonstrate the impact of academic detailing on clinical practice.

In an effort to improve patient care, we conducted an educational, quality improvement study to investigate the use of academic detailing combined with in-person reminders by a pharmacist to improve resident knowledge of the need to monitor for iron deficiency in patients with CHF as measured by total number of iron levels ordered by residents and results of pre- and post-intervention surveys.

\section{Methods}

Cone Health Family Medicine Center is a community-based family medicine residency clinic with 24 residents and eight faculty physicians located in Greensboro, North Carolina. From this practice, we identified a cohort of 488 patients with CHF. We performed a systematic chart review to identify any serum iron levels drawn for these patients within the year prior to the start of our intervention, and we used the presence of an iron level as the monitoring parameter for iron deficiency. We defined iron deficiency as an iron level $<42 \mathrm{ug} / \mathrm{mL}$. We also developed a pre- and post-intervention, cross-sectional survey to assess resident knowledge of the association between iron deficiency and CHF. The survey asked residents to select which labs should be routinely monitored in $\mathrm{CHF}$ patients (Figure 1).

From September 2013 to April 2014, a pharmacist met individually with all 24 residents during a scheduled, one-time meeting that lasted on average 5 to 10 minutes. Occasionally, due to some residents' irregular schedules, these meetings occurred on more of an ad hoc basis. During this meeting, the pharmacist provided the resident with an educational handout including data detailing the association between $\mathrm{CHF}$ and iron deficiency, data showing improvement in CHF patients treated with supplemental iron, and the resident's specific patients with CHF at risk of iron deficiency (Figure 2).

After this initial meeting, the pharmacist sent periodic reminders about checking iron levels to the residents via the electronic medical record (EMR), but we discarded this practice after 1 month due to lack of resident response. Instead, the pharmacist individually met with each resident scheduled in clinic each day. These meetings lasted on average less than 5 minutes, and consisted of providing the residents with a list of their patients scheduled for clinic that day who had $\mathrm{CHF}$ and should be targeted for either checking an iron level or reviewing previous iron levels. These meetings occurred from November 2013 to April 2014.

We determined the number of iron levels each resident ordered by querying the EMR through an institutionalized report run weekly from Sept 2013 to May 2014. We used Fisher's exact test to evaluate the iron panel data and the pre- and post-intervention survey data with a $P$-value of $<0.05$ for statistical significance. As a secondary endpoint we also evaluated the effectiveness of different methods of communication with the residents. Initially we tabulated weekly the number of EMR reminders which led to iron levels being drawn, with plans to compare these to in-person reminders. This quality initiative was approved by the health system's institutional review board. 


\section{Results}

The systematic chart review revealed that only $16(3 \%)$ of $488 \mathrm{CHF}$ patients with diagnosed CHF had an iron level drawn anytime during the year preceding the intervention. Residents collected a total of 234 patients' iron levels after the intervention $(P<0.0001)$. Of those collected, $98(42 \%)$ were determined to be iron deficient (iron $<42 \mathrm{ug} / \mathrm{mL}$ ) (Figure 3), with a mean iron level of $27 \mathrm{ug} / \mathrm{mL}(\mathrm{SD}+/-9.8)$. Iron deficiency was diagnosed in both systolic and diastolic heart failure patients.

All 24 residents completed the initial survey. Prior to the intervention, only one of the 24 residents (4.2\%) reporting knowledge of the importance of monitoring iron in CHF patients (Figure 4). Twenty of the 24 residents completed the post-intervention survey. Of those who completed the survey, all 20 residents reported that they would monitor iron in patients with CHF, a statistically significant improvement from the initial survey $(P<0.001)$.

The pharmacist sent each resident with whom she had met an average of three to four EMR messages during the first month of the intervention to remind them to order an iron level for their CHF patients. The use of EMR messages to the residents was not effective, with less than five total messages leading to residents ordering iron levels for these patients. Due to this lack of response, we stopped this practice and switched to using in-person reminders. Because we only had 1 month of data for these EMR reminders, we did not assess results comparing EMR versus in-person reminders. Residents informally reported that they preferred in-person reminders over electronic requests, and that they were also more likely to act upon in-person requests.

\section{Discussion}

We found academic detailing, using in-person education, and in-person same-day reminders from a pharmacist to be an effective means of increasing iron deficiency monitoring in CHF patients, while also improving resident awareness of the need to evaluate for iron deficiency in CHF patients. After initiation of the study, about $50 \%$ of the total number of patients in our clinic with documented CHF had an iron level drawn, as compared to just $3 \%$ of patients before the start of the study, a statistically significant increase. We found $20 \%$ of these patients to be iron deficient, a diagnosis which would likely otherwise have not been made based on the low number of patients with iron levels drawn at baseline.

These results are consistent with prior research showing an improvement in quality of care after incorporating academic detailing into everyday practice. ${ }^{5,6}$ Similarly, a Cochrane Systematic Review of 69 randomized trials of educational outreach visits-another term for academic detailing-also found an association with significant improvements in targeted behavior changes when using academic detailing. ${ }^{18}$

Limitations of our study include the small study population, the lack of a control group, no cost analysis, no longitudinal evaluation, the Hawthorne observer effect, and no direct comparison between academic detailing and EMR messages. Another limitation is that we did not investigate whether academic detailing by a pharmacist itself was responsible for the observed changes, or if the intensive reminder system was more impactful, but the combination of these two approaches provided meaningful change. A final limitation regarding resident feedback was that we abandoned use of EMR reminders to residents after only 1 month. As stated in the results, less than five EMR reminders led to residents ordering iron panels, and therefore we switched to operating solely with in-person reminders.

Academic detailing and in-person, same-day reminders by a pharmacist is a viable educational outreach option in a family medicine residency. As health care systems move from a fee-for-service environment to value-driven payment, academic detailing can be used to both improve the quality of care provided to patients in resident teaching clinics and introduce teaching about quality metrics. Educational programs can look to other health care professionals to provide this much needed service.

\section{Tables and Figures}


Figure 1: Resident Survey

1. Please check your current resident year.

$\square 1^{\text {st }}$ year $\square 2^{\text {nd }}$ year $\square 3^{\text {rd }}$ year

2. Please check how comfortable you feel managing heart failure, on a scale of 1-10. $1=$ completely uncomfortable, $10=$ very comfortable.

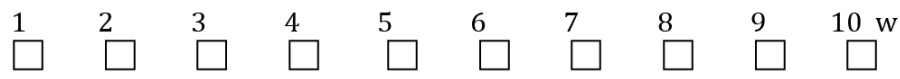

3. Please check which labs you would routinely monitor in a patient with heart failure.

\begin{tabular}{lll}
$\square$ BNP & $\square$ Glucose & $\square$ Chloride \\
$\square$ Hgb/Hct & $\square$ LFTs & $\square$ Phosphorus \\
$\square$ Potassium & $\square$ SCr/BUN & $\square$ Sodium \\
$\square$ WBC & $\square$ Iron \\
\hline Other &
\end{tabular}


Figure 2: Pharmacist Handout

Background:

Studies suggest that anywhere from $5 \%$ to $21 \%$ of chronic heart failure patients have iron deficiency anemia. There are many mechanisms through which this deficiency may occur, such as poor nutrition, decreased absorption of dietary iron, long-term aspirin use, and uremic gastritis. Iron deficiency in chronic heart failure patients can worsen outcomes. It may reduce exercise capacity and change the structure of cardiac myocytes. Iron deficiency is also associated with impaired exercise capacity and survival.

Current data show that treatment of iron deficiency in chronic heart failure can improve quality of life and function

A large randomized, placebo-controlled trial, FAIR-HF, compared intravenous iron carboxymaltose with placebo in both non-anemic and anemic (hemoglobin $<12 \mathrm{~g} / \mathrm{dL}$ ) chronic heart failure patients with iron deficiency. Iron deficiency was defined as ferritin $<100 \mathrm{ug} / \mathrm{L}$ or $100-299 \mathrm{ug} / \mathrm{L}$ with a transferrin saturation $<20 \%$. $82 \%$ of patients had NYHA class III symptoms and the mean serum ferritin leve was $52 \mathrm{ug} / \mathrm{L}$. The results are as follows:

\begin{tabular}{|l|c|c|c|}
\hline Results for FAIR-HF & $\begin{array}{c}\text { Ferric } \\
\text { carboxymaltose }\end{array}$ & Placebo & $P$-value \\
\hline $\begin{array}{l}\text { Patient Global } \\
\text { Assessment Score } \\
\text { Improvement }\end{array}$ & $50 \%$ of patients & $28 \%$ of patients & $P<0.001$ \\
\hline $\begin{array}{l}\text { NYHA functional Class } \\
\text { Improvement }\end{array}$ & $47 \%$ of patients & $30 \%$ of patients & $P<0.001$ \\
\hline
\end{tabular}

The results were observed in both anemic and non-anemic patients.

Similar results have been seen in other trials. In FERRIC-HF, chronic heart failure patients were given intravenous iron sucrose or placebo. Around $55 \%$ of patients where NYHA functional class II and $45 \%$ class III. Baseline ferritin was $88 \mathrm{ng} / \mathrm{ml}$ in the control group and $62 \mathrm{ng} / \mathrm{ml}$ in the iron sucrose group.

\begin{tabular}{|l|c|c|c|}
\hline Results for FERRIC-HF & Iron sucrose & Placebo & $P$-value \\
\hline $\begin{array}{l}\text { Patient Global } \\
\text { Assessment Score } \\
\text { Improvement }\end{array}$ & 1.5 points & 0.2 points & $P=0.002$ \\
\hline $\begin{array}{l}\text { NYHA functional Class } \\
\text { Improvement }\end{array}$ & $44 \%$ of patients & $0 \%$ of patients & $P=0.03$ \\
\hline
\end{tabular}

Another trial, IRON-HF, compared intravenous iron sucrose and oral ferrous sulfate in chronic heart failure patients. It was terminated early due to lack of enrollment but the data showed a trend that iron replacement improved functional capacity. 
Figure 3: Iron Deficiency Results Post-intervention

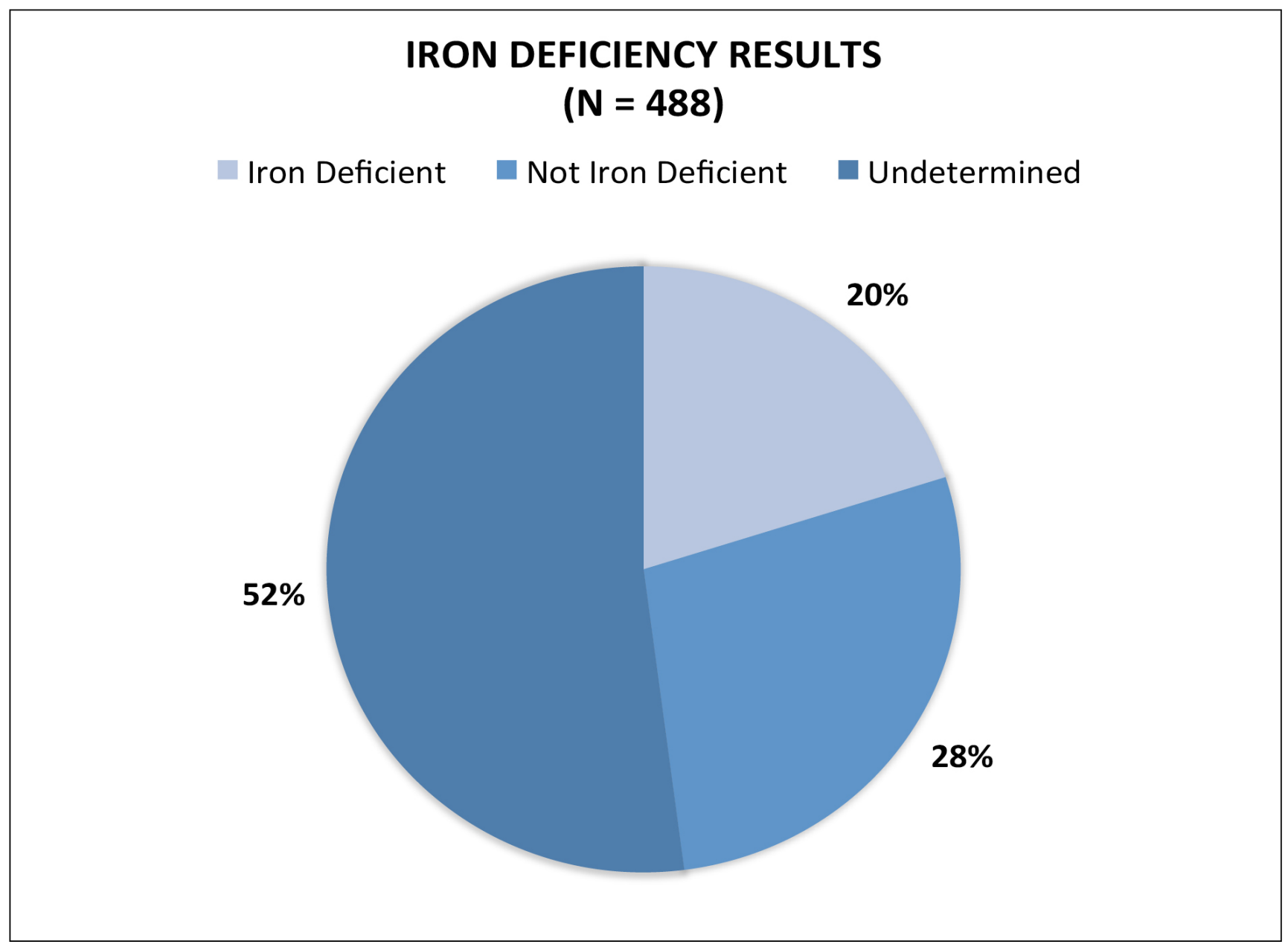




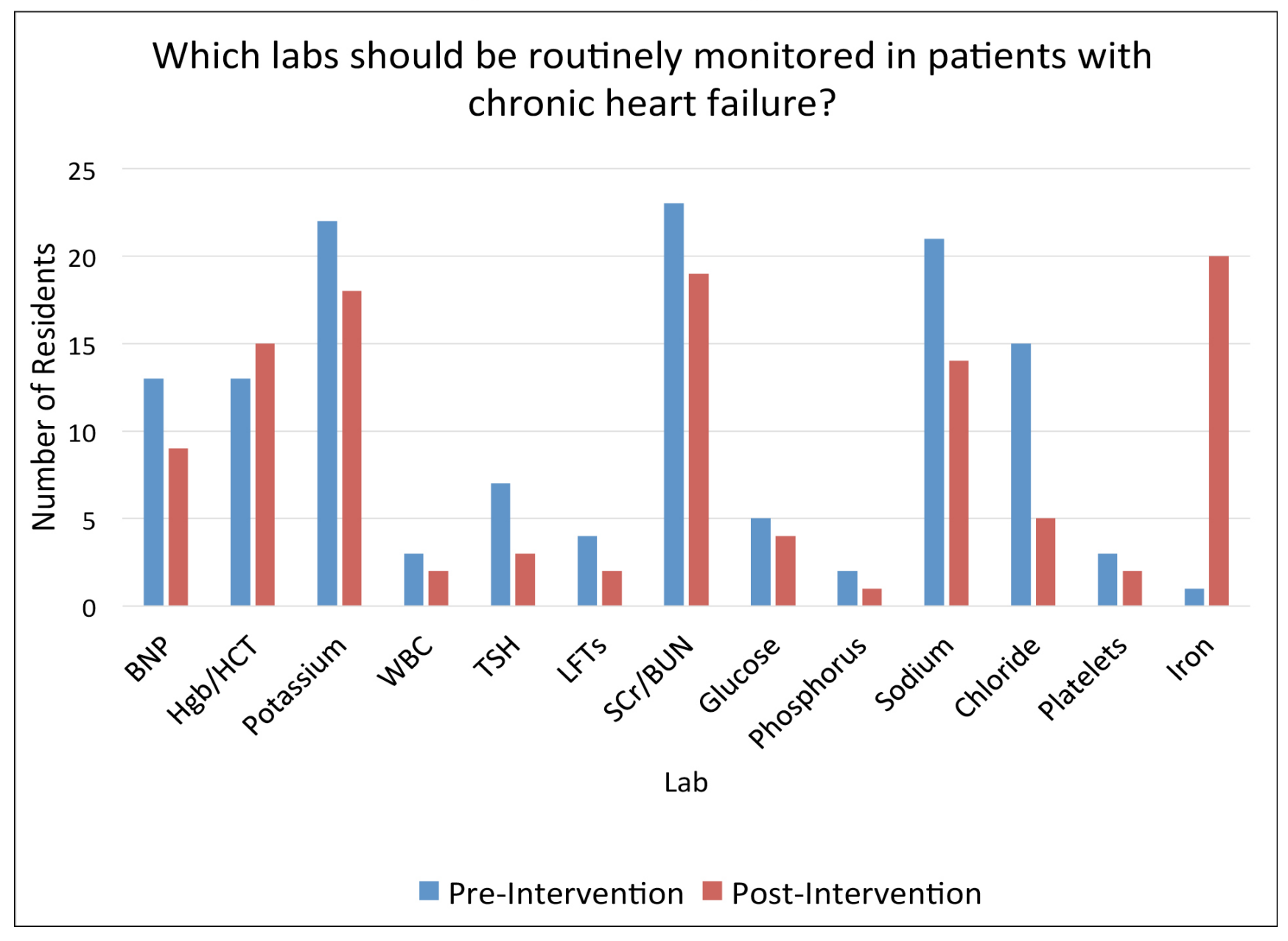

\section{Acknowledgements}

The authors acknowledge Marshall Lee Chambliss, MD, for assistance with academic detailing and framework of study.

\section{Presentations:}

Karl SA, Walden JH, Koval PG, Chambliss ML. Academic detailing by a pharmacist in a family medicine residency program. Poster session presented at: Society of Teachers of Family Medicine $49^{\text {th }}$ Annual Spring Conference; 2016 April 30-May 4; Minneapolis, MN.

\section{Corresponding Author}

Stacey Karl, PharmD, BCPS

Cone Health, 1125 N. Church St., Greensboro, NC 27401. 336-337-3566. Fax: 336-832-8094

stacey.karl@conehealth.com

\section{Author Affiliations}

Stacey Karl, PharmD, BCPS - Cone Health, Greensboro, NC

Jeffrey Walden, MD - Cone Health Family Medicine Residency, Greensboro, NC

Peter Koval, PharmD, BCPS - Cone Health Family Medicine Residency

\section{References}


1. Chassin MR, Galvin RW. National Roundtable on Health Care Quality. The urgent need to improve health care quality: Institute of Medicine national roundtable on health care quality. J Am Med Assoc. 1998;

280:1000-1005.

https://doi.org/10.1001/jama.280.11.1000.

2. Agency for Healthcare Research and Quality. 2010 national healthcare disparities report. AHRQ Publication No. 11-0005. March 2011. http://archive.ahrq.gov/research/findings/nhqrdr/nhdr10/nhdr10.pdf. Accessed March 12, 2016.

3. Berwick DM, Nolan TW, Whittington J. The triple aim: care, health, and cost. Health Aff (Millwood). 2008;27(3):759-769. https://doi.org/10.1377/hlthaff.27.3.759.

4. Centers for Disease Control and Prevention. Academic detailing: frequently asked questions. March 2014. http://www.cdc.gov/tobacco/quit_smoking/cessation/pdfs/academic-detailing-faq.pdf. Accessed February 1, 2016.

5. Solomon DH, Van Houten L, Glynn RJ, et al. Academic detailing to improve use of broad-spectrum antibiotics at an academic medical center. Arch Intern Med. 2001;161(15):1897-1902.

https://doi.org/10.1001/archinte.161.15.1897.

6. Hartung DM, Ann Hamer, Middleton, L, et al. A pilot study evaluating alternative approaches of academic detailing in rural family practice clinics. BMC Fam Pract. 2012;13:129. https://doi.org/10.1186/1471-2296-13-129

7. Hughes LS, Tuggy M, Pugno $P$, et al. Transforming training to build the family physician workforce our country needs. Fam Med. 2015;47(8):620-627.

8. Go AS, Mozaffarian D, Roger VL, et al. Heart disease and stroke statistics - 2013 update: a report from the American Heart Association. Circulation. 2013;127:e6-e245. https://doi.org/10.1161/CIR.0b013e31828124ad.

9. Heidenreich PA, Trogdon JG, Khavjou OA, et al. Forecasting the future of cardiovascular disease in the United States: a policy statement from the American Heart Association. Circulation. 2011;123(8):933-44. https://doi.org/10.1161/CIR.0b013e31820a55f5.

10. Dec GW. Anemia and iron deficiency - new therapeutic targets in heart failure? N Engl J Med. 2009;361:2475-7. https://doi.org/10.1056/NEJMe0910313.

11. Brownlie TT, Utermohlen V, Hinton PS, et al. Tissue iron deficiency without anemia impairs adaptation in endurance capacity after aerobic training in previously untrained women. Am J Clin Nutr. 2004;79:437- 43.

12. Dong $F$, Zhang $X$, Culver $B$, et al. Dietary iron deficiency induces ventricular dilation, mitochondrial ultrastructural aberrations and cytochrome $c$ release: involvement of nitric oxide synthase and protein tyrosine nitration. Clin Sci (Lond). 2005;109:277- 286.

https://doi.org/10.1042/CS20040278.

13. Okonko DO, Mandal KJ, Missouris CG, et al. Disordered iron homeostasis in chronic heart failure. J Am Coll Cardiol. 2011;58:1241-1251. https://doi.org/10.1016/j.jacc.2011.04.040.

14. Anand IS. Anemia and chronic heart failure: implications and treatment options. J Am Coll Cardiol. 2008;52:501-11. https://doi.org/10.1016/j.jacc.2008.04.044.

15. Anker SD, Comin CJ, Filippatos G, et al. Ferric carboxymaltose in patients with heart failure and iron deficiency. N Engl J Med. 2009;361:2436-2448. https://doi.org/10.1056/NEJMoa0908355.

16. Ponikowski P, Voors AA, Anker SD, et al. 2016 ESC Guidelines for the diagnosis and treatment of acute and chronic heart failure. Eur Heart J. 2016;37:2129-2200.

https://doi.org/10.1093/eurheartj/ehw128.

17. Yancey CW, Jessup M, Bozkurt B, et al. 2013 ACCF/AHA Guideline for the Management of Heart Failure. Circ. 2013;12:e240-e327. 
https://doi.org/10.1016/j.jacc.2013.05.019.

18. O'Brien MA, Rogers S, Jamtvedt G, et al. Educational outreach visits: effects on professional practice and health care outcomes. Cochrane Database Syst Rev. 2007;(4):CD000409.

https://doi.org/10.1002/14651858.CD000409.pub2.

Copyright $(\subset) 2017$ by the Society of Teachers of Family Medicine 